\title{
Estrogen Induces Estrogen Receptor $\alpha$-Dependent cAMP Response Element-Binding Protein Phosphorylation via Mitogen Activated Protein Kinase Pathway in Basal Forebrain Cholinergic Neurons In Vivo
}

\author{
Éva M. Szegő, ${ }^{1}$ Klaudia Barabás, ${ }^{1}$ Júlia Balog, ${ }^{1}$ Nóra Szilágyi, ${ }^{1}$ Kenneth S. Korach,,${ }^{2}$ Gábor Juhász, ${ }^{1}$ and \\ István M. Abrahám ${ }^{1}$ \\ ${ }^{1}$ Neurobiology Research Group, Hungarian Academy of Sciences, Eötvös Loránd University, H-1117 Budapest, Hungary, and ${ }^{2}$ Receptor Biology Section, \\ Laboratory of Reproductive and Developmental Toxicology, National Institute of Environmental Health Sciences, Research Triangle Park, North Carolina \\ 27709
}

In addition to classical genomic mechanisms, estrogen also exerts nonclassical effects via a signal transduction system on neurons. To study whether estrogen has a nonclassical effect on basal forebrain cholinergic system, we measured the intensity of cAMP response element-binding protein (CREB) phosphorylation (pCREB) in cholinergic neurons after administration of $17 \beta$-estradiol to ovariectomized (OVX) mice. A significant time-dependent increase in the number of pCREB-positive cholinergic cells was detected after estrogen administration in the medial septum-diagonal band (MS-DB) and the substantia innominata (SI). The increase was first observed $15 \mathrm{~min}$ after estrogen administration. The role of classical estrogen receptors (ERs) was evaluated using ER knock-out mice in vivo. The estrogeninduced CREB phosphorylation in cholinergic neurons was present in ER $\beta$ knock-out mice but completely absent in ER $\alpha$ knock-out mice in MS-DB and SI. A series of in vitro studies demonstrated that estrogen acted directly on cholinergic neurons. Selective blockade of the mitogen activated protein kinase (MAPK) pathway in vivo completely prevented estrogen-induced CREB phosphorylation in cholinergic neurons in MS-DB and SI. In contrast, blockade of protein kinase A (PKA) was effective only in SI. Finally, studies in intact female mice revealed levels of CREB phosphorylation within cholinergic neurons that were similar to those of estrogen-treated OVX mice. These observations demonstrate an $\mathrm{ER} \alpha$-mediated nonclassical effect of estrogen on the cholinergic neurons and that these actions are present under physiological conditions. They also reveal the role of MAPK and PKA-MAPK pathway activation in nonclassical estrogen signaling in the basal forebrain cholinergic neurons in vivo.

Key words: steroid; ChAT; nongenomic; transgenic mice; signaling pathways; estrogen

\section{Introduction}

The basal forebrain cholinergic system (BFC) provides a substantial source of cholinergic projections to the cortex and hippocampus and plays a pivotal role in cortical arousal, attention, and cognitive functions (Beninger et al., 1989; Zaborszky et al., 1999). Recent investigations demonstrate that estrogen regulates the function of cholinergic neurons that project to the cortex and hippocampus (McEwen, 2002; Gabor et al., 2003). Disruption of

\footnotetext{
Received Jan. 17, 2006; revised March 2, 2006; accepted March 9, 2006.

This work was supported by National Science Research Grants 0TKA \#047217 (I.M.A.) and 0TKA \#044711 (G.J., I.M.A.), a Marie Curie Reintegration grant (I.M.A.), National Office of Research and Technology Grant NKTHMEDICHEMII (to G.J.), Regional Center of Excellence-Neurobiological Center of Excellence in Southern Hungary (RET-DNK (to G.J.), a Richter Centenarium Research grant (I.M.A.), and a Bolyai János fellowship (I.M.A.). We thank Prof. Allan Herbison, Dr. Péter Batáry, and Attila Kaszás for valuable comments on this manuscript. We thank Dr Márk Oláh and Lajosné Szentmiklósi for radioimmunoassay work and Dr. Miklós Sárvári for the assistance in immunohistochemical studies.

Correspondence should be addressed to Dr. István M. Ábrahám, Neurobiology Research Group, Hungarian Academy of Sciences, Pázmány st 1/c, H-1117 Budapest, Hungary. E-mail: abraham@dec001.geobio.elte.hu. DOI:10.1523/JNEUROSCI.0222-06.2006

Copyright $\odot 2006$ Society for Neuroscience $\quad 0270-6474 / 06 / 264104-07 \$ 15.00 / 0$
}

BFC produces a deficit in attention and learning as well as a decline in reference memory, and BFC neurons are particularly vulnerable in Alzheimer's and Parkinson's diseases (Whitehouse et al., 1982; Coyle et al., 1983; Wenk et al., 1998). Among many different factors controlling the vulnerability of cholinergic neurons, the gonadal steroid estrogen is one of the essential contributors. In fact, administration of estrogen can restore synaptic connectivity in the cerebral cortex after the loss of subcortical cholinergic input without rescuing BFC cells against excitotoxic cell death (Aggarwal and Gibbs, 2000; Horvath et al., 2002). Moreover, gender differences in Alzheimer's and Parkinson's diseases suggest a possible role of gonadal steroids in cytoprotection (Leranth et al., 2000; Maccioni et al., 2001; Gibbs, 2003; Saunders-Pullman, 2003; Baum, 2005). Although estrogenic effects on the expression of cholinergic enzymes were among the first nonreproductive gonadal steroid actions disclosed in the nervous system (Gibbs et al., 1997, 2004), its molecular mechanisms in cholinergic neurons are still unknown.

Estrogen receptors (ERs) are present in cholinergic neurons, with mainly ER $\alpha$ found in BFC neurons (Shughrue et al., 2000; 
Kalesnykas et al., 2005). Generally, estrogen affects neurons two different ways: either via direct DNA-binding and transcriptional activity of liganded ERs (classical effect) or via rapid intracellular signaling pathways activation through protein kinase A (PKA) and mitogen activated protein kinase (MAPK) (Carlstrom et al., 2001; Kim et al., 2002; Guerra et al., 2004; Vasudevan et al., 2005; Zhao et al., 2005). We define this action of estrogen as nonclassical effect, because this downstream process indirectly acts on gene transcription via signaling pathways. The common target of many signaling pathways is a key transcription factor, the cAMP response element (CRE)-binding protein (CREB). Cellular signaling mechanisms activate the phosphorylation of CREB (pCREB), which is required for CREB to become a transcriptional regulator (Gonzalez et al., 1989; Mayr and Montminy, 2001). Previous findings suggest a crucial role of CREB-regulated transcriptional machinery in the control of neuronal vulnerability (Tao et al., 1998; Pugazhenthi et al., 2000; Lonze and Ginty, 2002; Saini et al., 2004).

A precise understanding of the effects of estrogen on any neuronal cell type requires information on the estrogen-sensitive classical and nonclassical effects. In the present study, we focused on the estrogen-induced nonclassical actions. Using CREB phosphorylation as an index of intracellular alterations, we characterized the estrogen-induced signaling in BFC neurons. Our findings demonstrate direct, estrogen-induced, ER $\alpha$-mediated CREB phosphorylation via the PKA-MAPK pathway in BFC neurons.

\section{Materials and Methods}

Animals. The animal breeding and experiments were performed based on of rules of Local Animal Care Committee at the Eötvös Loránd University in accordance with the European Union conform Hungarian Act of Animal Care and Experimentation. Wild-type (WT) C57BL6/J mice and estrogen receptor $\alpha$ or $\beta$ knock-out (KO) mice [ER $\alpha \mathrm{KO}$ (Lubahn et al., 1993) or ER $\beta$ KO (Krege et al., 1998)] were maintained under a $12 \mathrm{~h}$ light/dark cycle at $20^{\circ} \mathrm{C}$, and they were supplied with water and food ad libitum.

In vivo studies. Adult female 45- to 60-d-old wild-type (C57BL/6J) mice were bilaterally ovariectomized (OVX) under Avertin anesthesia. On postovariectomy day 14 , animals received a subcutaneous injection of $33 \mathrm{ng} / \mathrm{g} 17 \beta$-estradiol (E2) in $0.1 \mathrm{ml}$ of ethyl-oleate vehicle (Sigma, Budapest, Hungary) or vehicle alone (V) between 8:00 and 10:00 A.M. In our previous studies, $33 \mathrm{ng} / \mathrm{g}$ E2 rapidly ( $<15 \mathrm{~min}$ ) induced CREB phosphorylation in the CNS (Abraham et al., 2003); therefore, animals were killed $15 \mathrm{~min}, 1 \mathrm{~h}$, or $4 \mathrm{~h}$ later by an overdose of Avertin $(0.015 \mathrm{ml} / \mathrm{g})$. Blood was taken for E2 radioimmunoassay (RIA), and mice were transcardially perfused with ice-cold 4\% paraformaldehyde, $\mathrm{pH} 7.6$ (Merck, Budapest, Hungary), in PBS solution. Brains were postfixed for $2 \mathrm{~h}$ at $4^{\circ} \mathrm{C}$ and cryoprotected in Tris-phosphate-buffered solution (TBS; pH 7.6) containing $30 \%$ sucrose (Sigma) overnight at $4^{\circ} \mathrm{C}$. Coronal sections, 30 $\mu \mathrm{m}$ thick, were cut on a freezing microtome, and four sets of sections were collected in TBS.

Based on PCR analysis, female homozygous ER $\alpha \mathrm{KO}$ mice, ER $\beta \mathrm{KO}$ mice, and wild-type siblings from both strains were selected. The experimental protocol was similar to those described above, with the exception that all of these mice were killed at 15 min after E2 injection.

In a separate experiment, we administered a selective PKA inhibitor $N$-[2-( $p$-bromocinnamylamino)ethyl]-5- isoquinolinesulfonamide dihydrochloride (H-89; Sigma) $[0.67 \mu \mathrm{g} / \mu \mathrm{l}$ in $10 \%$ dimethylsulfoxide (DMSO) in artificial CSF (ACSF) containing the following (in mM): 147 $\mathrm{Na}^{+}, 3.5 \mathrm{~K}^{+}, 2 \mathrm{Ca}^{2+}, 1 \mathrm{Mg}^{2+}, \mathrm{pH} 7.3$ ] or a mitogen-activated protein kinase kinase 1/2 (MEK1/2) inhibitor 1,4-diamino-2,3-dicyano-1,4bis[2-amino-phenylthio]butadiene (U0126; Cell Signaling Technology, Beverly, MA) $(0.1 \mu \mathrm{g} / \mu \mathrm{l}$ in $10 \%$ DMSO in ACSF) to OVX female wildtype mice. Two weeks after OVX, inhibitors were injected into the lateral ventricle (anteroposterior, -0.82 ; lateral, 1.50; dorsoventral, -1.50 to 1.70 from dura) under halothane $(1.5 \%$ in air) anesthesia. Control groups received 10\% DMSO in ACSF. Thirty minutes after injection of inhibitors or DMSO, animals received $33 \mathrm{ng} / \mathrm{g}$ E2 or V subcutaneously, and they were killed by an overdose of Avertin $(0.015 \mathrm{ml} / \mathrm{g})$ and perfused 15 min after E2 injection. The dose of the inhibitors and timing was established previously (Cervo et al., 1997; Han and Holtzman, 2000; Rahmouni et al., 2004).

To assess the role of CREB phosphorylation in cholinergic neurons under physiological conditions, female wild-type mice were OVX or sham operated (SHAM), and they were perfused 2 weeks later. The estrous stage of SHAM mice was assessed by examination of daily vaginal smear, and mice in proestrus were selected for perfusion.

Acute brain slice preparation for assessing CREB phosphorylation in vitro. An acute brain slice protocol was performed as described previously (Abraham et al., 2003). Female wild-type 45- to 60-d-old mice were OVX. On postovariectomy day 14 , animals were decapitated at $\sim 9: 00$ A.M., and brains were rapidly removed and placed in oxygenated, icecold cutting solution for $5 \mathrm{~min}$ containing the following (in $\mathrm{mm}$ ): 118 $\mathrm{NaCl}, 3 \mathrm{KCl}, 6 \mathrm{MgCl}_{2}, 0.5 \mathrm{CaCl}_{2}, 25 \mathrm{NaHCO}_{3}, 10 \mathrm{HEPES}$, and 11 glucose, $\mathrm{pH} 7.4$, when saturated with $95 \% \mathrm{O}_{2}$ and $5 \% \mathrm{CO}_{2}$ (Sigma). Coronal slices were cut in the horizontal plane $(300 \mu \mathrm{m})$ with a vibratome (VT1000; Leica, Nussloch, Germany), and they were preincubated for $1 \mathrm{~h}$ in normal ACSF solution saturated with $95 \% \mathrm{O}_{2}$ and $5 \% \mathrm{CO}_{2}$ containing the following (in mM): $118 \mathrm{NaCl}, 3 \mathrm{KCl}, 10 \mathrm{HEPES}, 1.2 \mathrm{MgCl}_{2}, 2.5 \mathrm{CaCl}_{2}, 25$ $\mathrm{NaHCO}_{3}, 11$ glucose, with or without $0.5 \mu \mathrm{m}$ tetrodotoxin (TTX; Sigma). Slices were transferred into ACSF containing $100 \mathrm{~nm}$ E2 in ethanol or into $<0.01 \%$ ethyl-alcohol solution as vehicle. Slices pretreated with TTX also received TTX in the incubating solution. Fifteen minutes later, slices were fixed in $4 \%$ paraformaldehyde at $4^{\circ} \mathrm{C}$ overnight. The following day, slices were transferred into TBS containing 30\% sucrose, and four sets of 30 $\mu \mathrm{m}$ coronal sections were cut on a freezing microtome and collected into TBS.

Immunohistochemistry. Free-floating, double-labeling, peroxidasebased immunohistochemistry was performed in the same manner as we reported previously with a slight modification (Abraham et al., 2003). In brief, sections were incubated with one of the primary antibodies (pCREB, 1:100; CREB, 1:100; Cell Signaling Technology) for $48 \mathrm{~h}$ at $4^{\circ} \mathrm{C}$. Subsequently, sections were incubated with biotinylated goat anti-rabbit IgG (1:200; Vector Laboratories, Burlingame, CA) for $2 \mathrm{~h}$. This was followed by treatment with Vector avidin-biotin-HRP complex (Vector Standard Elite kit, 1:200; Vector Laboratories) for 2 h. Peroxidase labeling was visualized by nickel-diaminobenzidine (DAB) tetrahydrochloride, using glucose oxidase. Sections were then processed for cholineacetyl-transferase (ChAT; 1:2000; Chemicon, Temecula, CA) peroxidase-based immunoreactivity (IR) (biotinylated goat anti-rabbit IgG, 1:200; avidin-biotin-HRP complex, 1:200 Vector Laboratories) and revealed using DAB only. The specificities of antibodies have been reported previously in rodent species (McNulty et al., 1998; von Gall et al., 1998) (Cell Signaling Technology data). The omission of primary antibodies resulted in a complete absence of immunoreactivity.

Estrogen RIA. Plasma estrogen concentrations were determined by RIA using a Third Generation Estradiol kit (DSL-39100; Diagnostic System Laboratories, Dallas, TX). The detection limit of estrogen was 0.6 $\mathrm{pg} / \mathrm{ml}$ from $100 \mu \mathrm{l}$ of plasma, the intra-assay coefficient of variation was $3.5 \%$, and the interassay coefficient of variation was $4.1 \%$.

Analysis. The number of immunoreactive cells was counted by an Olympus BX51 (Olympus Optical, Hamburg, Germany) microscope, using 20 and $40 \times$ objectives. Cholinergic neurons were only assigned to be representing CREB/pCREB, if the nucleus displayed a uniform black-IR product. Using the Paxinos and Franklin (2001) atlas, the following structures were selected for analysis: medial septum-diagonal band (MS-DB; plate 23-25), substantia innominata (SI; plate 34-35), and striatum (STR; plate 23-25). Two or three sections from each structure were selected, and the numbers of single (ChAT) and double-labeled (ChAT plus CREB or ChAT plus pCREB) neurons were determined by an investigator blind to the experimental groupings. CREB and PCREB expressions in ChAT-immunoreactive neurons were calculated as the percentage of total number of ChAT-immunoreactive neurons for each structure separately.

Statistical analysis. Data are expressed as mean + SEM, and square 


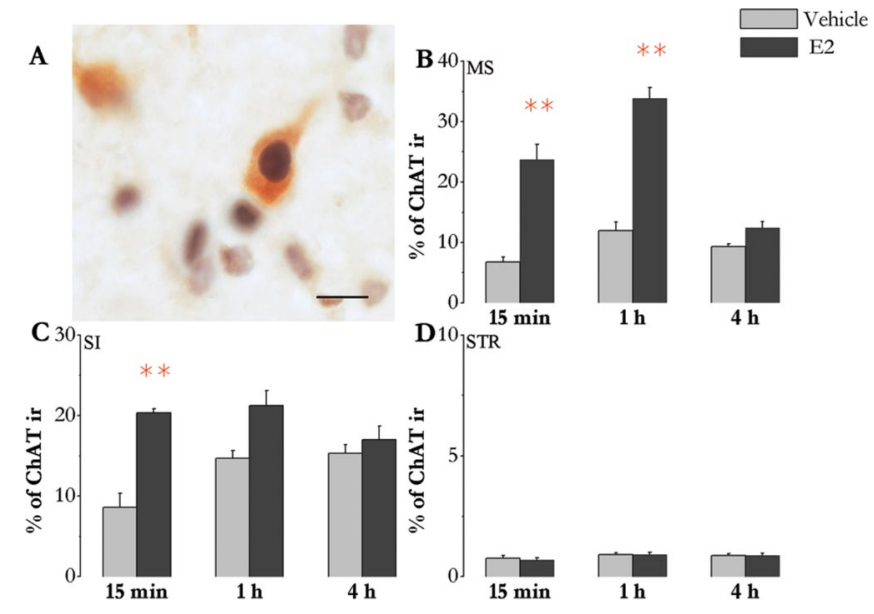

Figure 1. Estrogen rapidly induces CREB phosphorylation within cholinergic neurons in a time-dependent manner in vivo. The photomicrograph $(\boldsymbol{A})$ shows clear nuclear localized CREB-IR (black) within ChAT-immunopositive neuron (brown). Scale bar, $10 \mu \mathrm{m}$. Bar graphs show the percentage of cholinergic neurons expressing $p C R E B$ in the medial septum-diagonal band $(\boldsymbol{B})$, substantia innominata $(\boldsymbol{C}$, and striatum $(\boldsymbol{D})$ in wild-type mice treated with vehicle or estrogen. ${ }^{* *} p<0.01 ; n=6-8$ in all groups. Data are presented as mean + SEM.

root was transformed for ANOVA. To examine the differences between the groups of proestrus and intact mice, one-way ANOVA was used with Tukey's post hoc test. Two-way ANOVA with Tukey's post hoc test was used to determine differences between groups in all of the other experiments (Statistica 7.0; StatSoft, Tulsa, OK).

\section{Results}

Exogenously administered estrogen or ovariectomy effectively alters the plasma estradiol concentration

The reliability of the experimental groups was verified by the fact that E2 administration or ovariectomy effectively altered the plasma estradiol concentration. Treatment of OVX female mice with $33 \mathrm{ng} / \mathrm{g}$ E2 increased the plasma estradiol concentration to a supraphysiological level at all time points: $15 \mathrm{~min}$ (vehicle, $3.42 \pm$ $1.44 \mathrm{pg} / \mathrm{ml}$; E2, $854.39 \pm 197.45 \mathrm{pg} / \mathrm{ml} ; p<0.05$ ), $1 \mathrm{~h}$ (vehicle, $2.37 \pm 1.51 \mathrm{pg} / \mathrm{ml}$; $2,492.91 \pm 80.89 \mathrm{pg} / \mathrm{ml} ; p<0.05)$, and $4 \mathrm{~h}$ (vehicle, $6.01 \pm 0.38 \mathrm{pg} / \mathrm{ml}$; E2, $225.35 \pm 92.54 \mathrm{pg} / \mathrm{ml} ; p<0.05$ ). The plasma estradiol concentration in OVX mice was significantly lower than that in SHAM-operated animals in the stage of proestrus (OVX, $4.5 \pm 0.56 \mathrm{pg} / \mathrm{ml}$; SHAM, $49.52 \pm 5.57 \mathrm{pg} / \mathrm{ml}$; $p<0.05)$.

\section{Estrogen rapidly induces CREB phosphorylation in cholinergic neurons in vivo}

CREB-IR and pCREB-IR were clearly nuclear and easily detected in cholinergic neurons with double-labeling immunocytochemistry (Fig. 1A). Administration of $33 \mathrm{ng} / \mathrm{g}$ E2 to OVX wild-type female mice resulted in a significant increase in pCREB-IR by cholinergic neurons 15 min after E2 injection ( $p<0.01$ ), peaked at $1 \mathrm{~h}(p<0.01)$, and returned to the baseline at $4 \mathrm{~h}$ in MS-DB (Fig. $1 B$ ). In SI, E2-induced CREB phosphorylation in cholinergic neurons was significant at $15 \mathrm{~min}(p<0.01)$, but there was no significant difference in the CREB phosphorylation in cholinergic neurons at either 1 or $4 \mathrm{~h}$ after treatments (Fig. 1C). E2 had no effect in STR (Fig. 1D). The expression of CREB in cholinergic neurons and the total number of cholinergic cells were not altered by E2 treatment or by time in STR, SI, and MS-DB (Table 1).
Effect of estrogen on CREB phosphorylation in cholinergic neurons is mediated by ER $\alpha$

To disclose that estrogen-dependent phosphorylation of CREB in cholinergic neurons requires one of the classical ERs, we used OVX WT, ER $\beta \mathrm{KO}$, and $\mathrm{ER} \alpha \mathrm{KO}$ mice in our additional investigations. We administered $33 \mathrm{ng} / \mathrm{g}$ E2 and evaluated the pCREB expression in cholinergic neurons at $15 \mathrm{~min}$, when CREB phosphorylation in cholinergic neurons was significant in MS-DB and SI. Similarly to the WT mice, the treatment of WT littermates of the knock-out animals with $33 \mathrm{ng} / \mathrm{g}$ E2 significantly increased pCREB expression in cholinergic neurons in MS-DB and SI (Fig. $2 A, B$ ) but not in STR (Fig. $2 B$ ). Although reduced in magnitude in MS-DB (compared with WT; $p<0.05$ ) (Fig. $2 A$ ), this response was maintained in ER $\beta$ KO mice in MS-DB $(p<0.01)$ (Fig. $2 A)$ and SI $(p<0.01)$ (Fig. $2 B$ ). In contrast, E2 failed to induce CREB phosphorylation in ER $\alpha \mathrm{KO}$ mice in MS-DB and SI (Fig. 2A,B). Levels of pCREB in cholinergic neurons of vehicle-treated mice were not significantly different in the three animal groups (Fig. $2 A-C)$. The level of CREB within cholinergic neurons and the total number of cholinergic neurons were not altered by estrogen treatment (data not shown).

\section{E2-induced CREB phosphorylation in cholinergic neurons is sensitive to TTX}

To confirm that E2-induced CREB phosphorylation is the result of direct action of E2 on cholinergic cells, we investigated TTX sensitivity of CREB phosphorylation in SI and MS-DB. Experiments were done on acute brain slices. The number of cholinergic neurons (MS-DB, 118.2 \pm 4.2; SI, $66.1 \pm 3.4$; STR, $196.4 \pm 1.6$ ) and the percentage of cholinergic neurons containing CREB-IR (MS-DB, $93.3 \pm 1.2$; SI, $98.3 \pm 0.6$; STR, $90.1 \pm 1.2$ ) in slices were similar to those in the in vivo experiments at basal conditions. Although the basal level of pCREB was slightly higher in slices than in the in vivo experiments, treatment of brain slices with 100 nM E2 for 15 min significantly elevated pCREB expression within cholinergic neurons of MS-DB $(p<0.01)$ (Fig. $3 B)$ and SI $(p<$ 0.01 ) (Fig. $3 C$ ). E2-induced CREB phosphorylation was not effected in MS-DB $(p<0.01)$ (Fig. 3B) and SI $(p<0.01)$ (Fig. 3C) by TTX, which synaptically isolates cholinergic neurons. The number of cholinergic neurons expressing CREB was not changed by E2 or TTX (data not shown).

\section{PKA inhibitor blocks the E2-induced CREB phosphorylation} in cholinergic neurons in SI

To study the role of the cAMP-PKA pathway in E2-induced CREB phosphorylation in cholinergic neurons, we injected the selective PKA inhibitor $\mathrm{H}-89$ into the lateral ventricle $30 \mathrm{~min}$ before E2 administration. Similarly to the previously described in vitro and in vivo experiments, pCREB-IR of cholinergic neurons was significantly higher after intracerebroventricular vehicle and subcutaneous E2 administration in MS-DB $(p<0.01)$ (Fig. $4 A$ ) and in SI $(p<0.01)$ (Fig. $4 B)$, and there was no effect in STR (Fig. $4 C$ ) at $15 \mathrm{~min}$. Intracerebroventricular administration of $\mathrm{H}-89$ blocked the E2-induced CREB activation in the SI $(p<$ 0.01) (Fig. $4 B$ ) but not in MS-DB (Fig. 4A). The level of CREB expression of cholinergic neurons was not altered by treatments in either of the areas examined (data not shown).

\section{MEK1/2 inhibitor blocks the E2-induced CREB phosphorylation in cholinergic neurons in both MS-DB and SI}

To demonstrate whether the E2-induced CREB phosphorylation requires MAPK pathway in cholinergic neurons, we adminis- 
Table 1. Estrogen ( $33 \mathrm{ng} / \mathrm{g}$ ) had no effect on CREB expression within cholinergic neurons and the total number of ChAT-positive neurons in STR, MS-DB, and SI of WT mice 15 $\min , 1 \mathrm{~h}$, or $4 \mathrm{~h}$ after treatment

\begin{tabular}{|c|c|c|c|c|c|c|c|}
\hline \multirow[b]{3}{*}{ Area } & \multirow[b]{3}{*}{ Treatment } & \multicolumn{6}{|l|}{ Time } \\
\hline & & \multicolumn{2}{|l|}{$15 \mathrm{~min}$} & \multicolumn{2}{|l|}{$1 \mathrm{~h}$} & \multicolumn{2}{|l|}{$4 \mathrm{~h}$} \\
\hline & & $\%$ & Total & $\%$ & Total & $\%$ & Total \\
\hline \multirow[t]{2}{*}{ STR } & Vehicle & $91.6 \pm 1.6$ & $197.0 \pm 21$ & $90.9 \pm 0.6$ & $196.0 \pm 2.9$ & $91.8 \pm 1.2$ & $198.2 \pm 2.1$ \\
\hline & E2 & $89.4 \pm 0.5$ & $195.2 \pm 1.2$ & $90.1 \pm 0.9$ & $195.2 \pm 2.2$ & $89.5 \pm 1.7$ & $196.1 \pm 1.8$ \\
\hline \multirow[t]{2}{*}{ MS-DB } & Vehicle & $95.2 \pm 0.5$ & $120.6 \pm 3.6$ & $90.2 \pm 1.1$ & $119.3 \pm 1.9$ & $90.6 \pm 1.6$ & $117.3 \pm 1.2$ \\
\hline & E2 & $92.6 \pm 0.2$ & $117.1 \pm 2.2$ & $92.6 \pm 1.4$ & $120.0 \pm 2.6$ & $91.5 \pm 1.8$ & $121.9 \pm 2.9$ \\
\hline \multirow[t]{2}{*}{ SI } & Vehicle & $99.8 \pm 0.1$ & $67.2 \pm 4.2$ & $99.2 \pm 0.2$ & $70.3 \pm 4.1$ & $99.1 \pm 0.2$ & $71.2 \pm 3.5$ \\
\hline & E2 & $97.9 \pm 0.2$ & $69.4 \pm 5.3$ & $99.1 \pm 0.1$ & $69.6 \pm 3.9$ & $99.3 \pm 0.1$ & $72.6 \pm 3.7$ \\
\hline
\end{tabular}

Data in the first column of each time point demonstrate the percentage of ChAT-immunopositive neurons expressing CREB ( \pm SEM) (\%). Data in the second column of each time point demonstrate the total number of ChAT-immunopositive neurons ( \pm SEM) (Total); $n=5-7$.

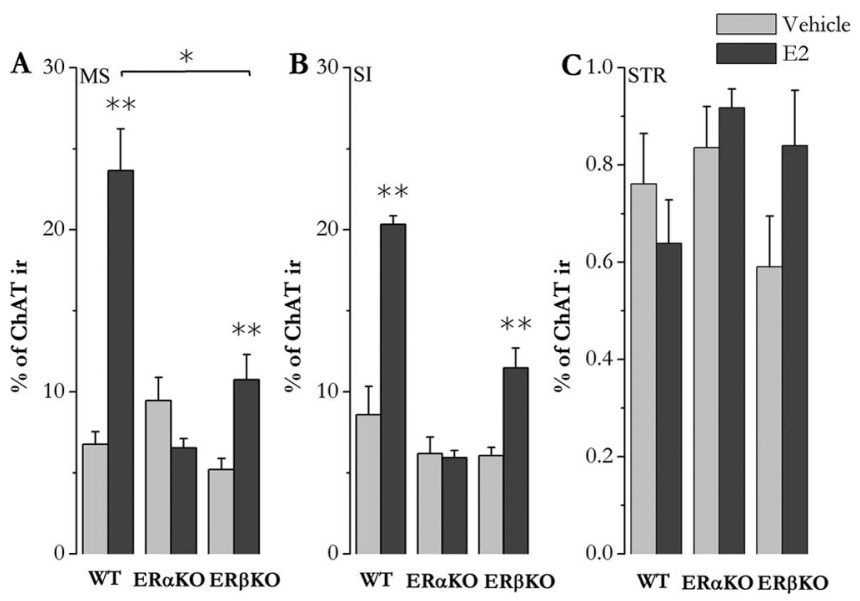

Figure 2. Estrogen requires ER $\alpha$ to induce CREB phosphorylation within cholinergic neurons in vivo. Bar graphs show the percentage of cholinergic neurons expressing $p C R E B$ in the medial septum-diagonal band $(\boldsymbol{A})$, substantia innominata $(\boldsymbol{B})$, or striatum $(\boldsymbol{C})$ in wild-type, ER $\alpha K 0$, and ER $\beta K O$ mice 15 min after vehicle or estrogen administration. ${ }^{* *} p<0.01 ;{ }^{*} p<0.05 ; n=$ $4-8$ in all groups. Data are presented as mean + SEM.

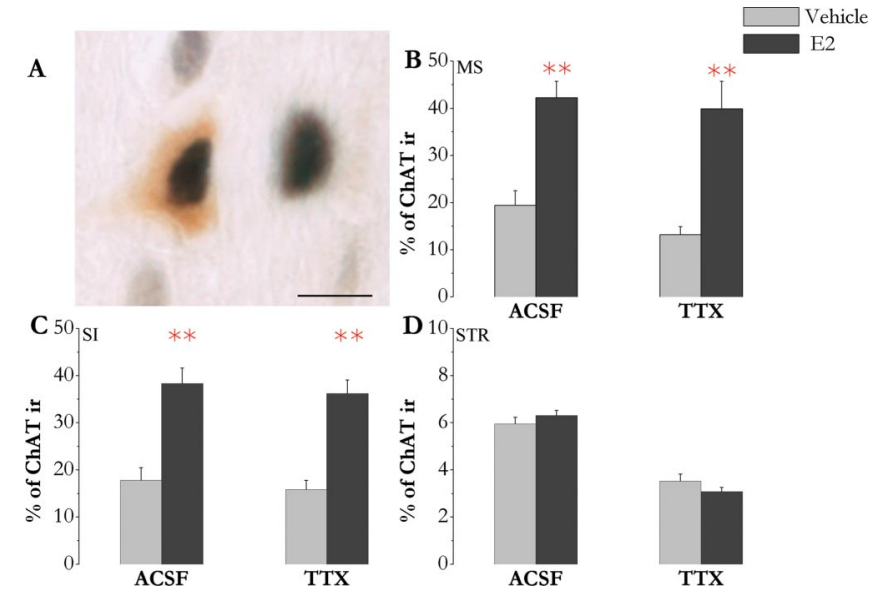

Figure 3. In the in vitro studies, estrogen rapidly and directly induces CREB phosphorylation within cholinergic neurons. The photomicrograph $(\boldsymbol{A})$ presents nuclear pCREB-IR (black) within a cholinergic neuron (ChAT-IR; brown). Scale bar, $10 \mu \mathrm{m}$. Bar graphs show the percentage of cholinergicneurons expressing pCREB in the medial septum-diagonal band $(\boldsymbol{B})$, substantia innominata $(\boldsymbol{C})$, or striatum $(D) 15 \mathrm{~min}$ after vehicle or estrogen treatment in the presence of ACSF or $0.5 \mu \mathrm{m}$ TTX in ACSF (TTX). ${ }^{* *} p<0.01 ; n=6-8$ in all groups. Data are presented as mean + SEM.

tered the MEK1/2 [the activating kinase for ERK1/2 (extracellular signal-regulated kinase)] inhibitor U0126 into the lateral ventricle $30 \mathrm{~min}$ before E2 injection. Similarly to previously described

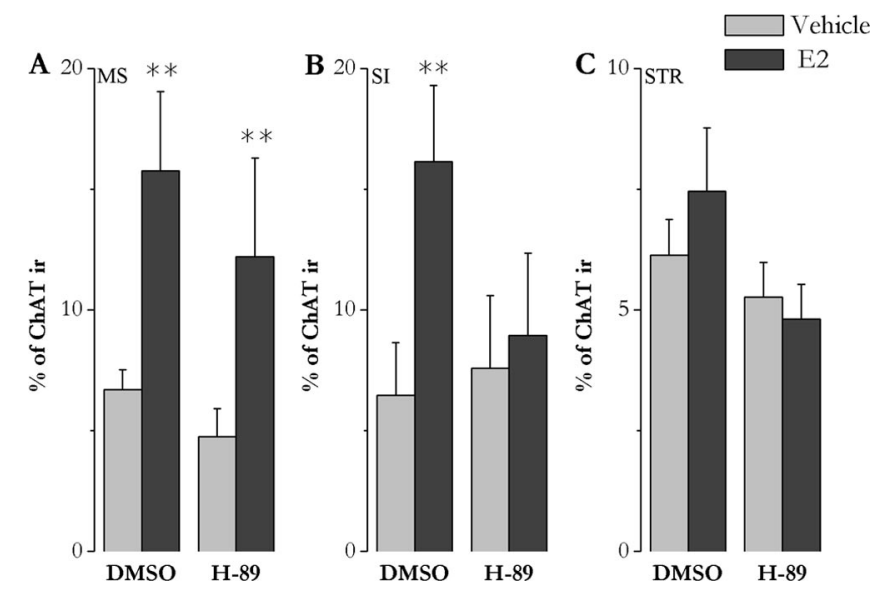

Figure 4. PKA dependence of estrogen-induced CREB phosphorylation within cholinergic cells shows a region difference in vivo. Bar graphs show the percentage of cholinergic neurons expressing pCREB within the medial septum-diagonal band $(\boldsymbol{A})$, substantia innominata $(\boldsymbol{B})$, or striatum $(C)$ in the presence of intracerebroventricularly administered DMSO or PKA inhibitor (H-89) 15 min after vehicle or estrogen injection. ${ }^{* *} p<0.01 ; n=5-6$. Data are presented as mean + SEM.

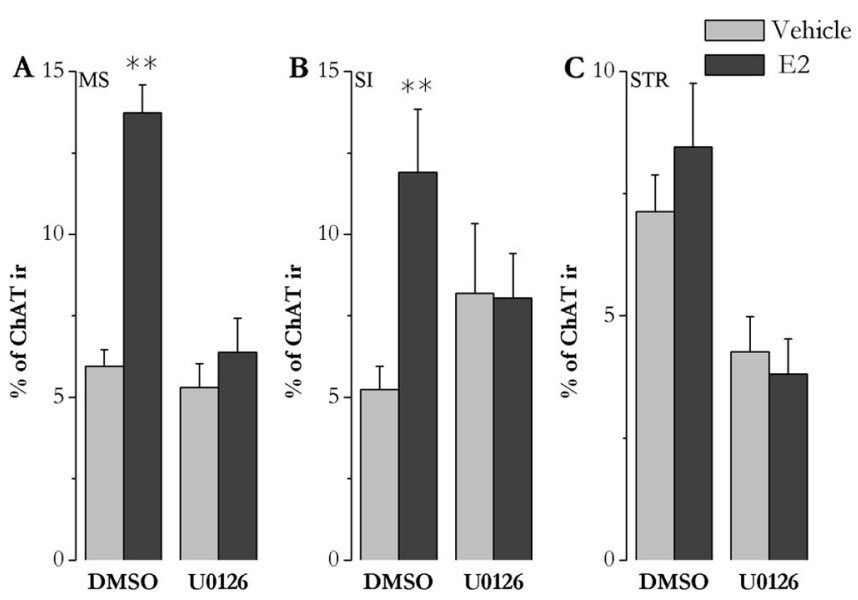

Figure 5. Estrogen-induced CREB phosphorylation within cholinergic cells is dependent on MAPK activation in vivo. Bar graphs show the percentage of cholinergic neurons expressing $\mathrm{pCREB}$ within the medial septum-diagonal band $(\boldsymbol{A})$, substantia innominata $(\boldsymbol{B})$, or striatum $(C)$ in the presence of intracerebroventricularly administered DMSO or MEK1/2 inhibitor (U0126) 15 min after vehicle or estrogen injection. ${ }^{* *} p<0.01 ; n=5-6$. Data are presented as mean + SEM.

experiments, E2 induced CREB phosphorylation in cholinergic neurons in MS-DB $(p<0.01)$ (Fig. 5A) and SI $(p<0.01)$ (Fig. $5 B$ ), and there was no effect in STR (Fig. $5 C$ ). In contrast, intra- 


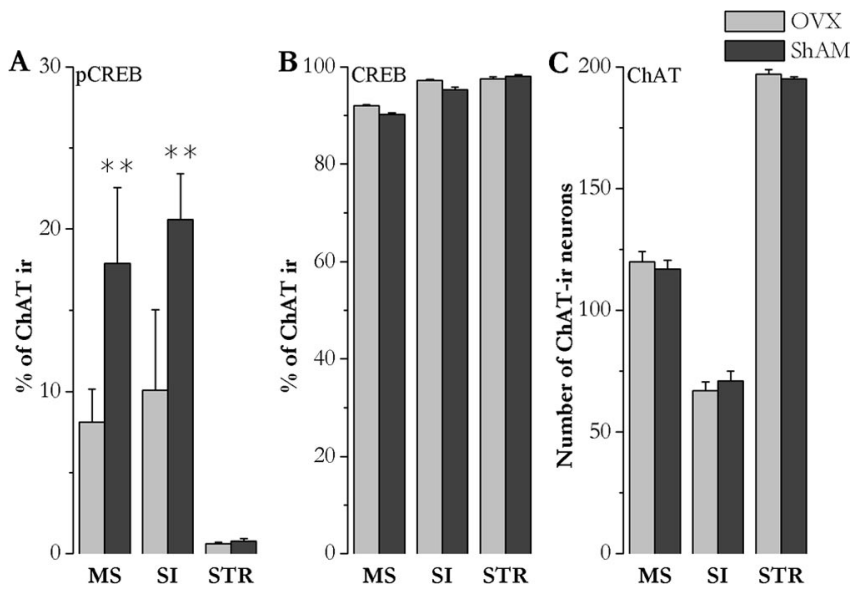

Figure 6. Phosphorylation of CREB is elevated in intact female mice during proestrus, compared with OVX control in vivo. Bar graphs demonstrate percentage of cholinergic neurons expressing pCREB $(\boldsymbol{A})$, CREB $(\boldsymbol{B})$, or the number of ChAT-immunopositive cells $(\boldsymbol{C})$ in the medial septum-diagonal band, striatum, and substantia innominata. ${ }^{* *} p<0.01 ; n=5-6$ in all groups. Data are presented as mean + SEM.

cerebroventricular administration of U0126 completely blocked the E2-induced CREB phosphorylation within cholinergic neurons in both MS-DB and SI (Fig. 5A,B). The level of CREB expression by cholinergic neurons was not altered in this experiment (data not shown).

\section{Levels of pCREB in cholinergic neurons remain elevated in intact female mice during proestrus}

To verify that rapid increase in the E2-induced CREB phosphorylation in cholinergic neurons could occur under normal physiological elevation in estrogen level, we compared OVX mice to intact SHAM-operated proestrus females. In intact proestrus mice, the level of pCREB in MS-DB $(p<0.01)$ and SI $(p<0.01)$ was significantly higher than in OVX animals, but there was no effect in STR (Fig. 6A). CREB expressions within cholinergic neurons and the number of cholinergic neurons were not altered by OVX (Fig. $6 B, C)$.

\section{Discussion}

We report here that E2 can rapidly ( $<15 \mathrm{~min}$ ) induce CREB phosphorylation in cholinergic neurons in vivo in SI and MS-DB on an ER $\alpha$-mediated pathway. TTX insensitivity of E2-induced CREB phosphorylation confirms that this is a direct effect of E2 on cholinergic cells. Estrogen appears to induce CREB phosphorylation via the MAPK pathway in MS-DB and SI. Blocking PKA resulted in inhibition of estrogen-induced CREB phosphorylation in SI but not in MS-DB, suggesting the existence of regionspecific estrogen-induced PKA-dependent CREB phosphorylation in BFC neurons.

\section{The possible mechanism of estrogen-induced CREB phosphorylation in basal forebrain cholinergic neurons} A great body of evidence suggests that estrogen exerts nonclassical effects in a variety of cell types. In immune cells (KarpuzogluSahin et al., 2001; Grimaldi et al., 2005), smooth muscle cells (Rossi et al., 2002; Hertelendy and Zakar, 2004), and endothelial cells, estrogen can rapidly alter the availability of second messengers (Zhu and Smart, 2003; Simoncini et al., 2004). Stimulation of the second messenger system may result in activation of transcription factors such as CREB. It is important to note that the rapidness of the actions of estrogen on CREB phosphorylation
( $<15 \mathrm{~min}$ ) suggests a nonclassical mechanism, because studies demonstrated that blockade of protein synthesis or gene transcription are ineffective in altering CREB phosphorylation in such a narrow time frame (Falkenstein et al., 2000).

In the CNS, CREB can be phosphorylated via synaptic activation (Matthies et al., 1997; Lee et al., 2005). Because the cholinergic neurons are not the only ones containing classical ERs in the septal region and SI (Shughrue et al., 2000), it is likely that estrogen-induced CREB phosphorylation in cholinergic cells was initiated via transsynaptic processes. However, we demonstrated that TTX could not eliminate the estrogen-induced CREB activation, and thus our data suggest that estrogen acts directly on cholinergic neurons.

In the nervous system, quantitative immunohistochemical studies demonstrated that E2 can initiate CREB phosphorylation in vitro and in vivo as well. In vivo studies reveal that $\mathrm{E} 2$ can induce CREB phosphorylation in dorsal root ganglion cells (PurvesTyson and Keast, 2004), anteroventral periventricular nucleus (Gu et al., 1996), bed nucleus of the stria terminalis (Zhou et al., 1996), medial preoptic area (Abraham et al., 2004), and hippocampus (Abraham and Herbison, 2005). However, little attention was given to the neuronal cell type specificity of estrogeninduced CREB phosphorylation. Previously, we demonstrated that estrogen can directly and rapidly induce the phosphorylation of CREB in gonadotropin-releasing hormone ( $\mathrm{GnRH})$ neurons via $\operatorname{ER} \beta$ (Abraham et al., 2003), and here we demonstrated that estrogen increases the pCREB expression in basal forebrain cholinergic neurons as well. However, there is a significant difference in E2-induced CREB phosphorylation between the two neuronal cell types. In GnRH neurons, CREB phosphorylation remained significantly elevated $4 \mathrm{~h}$ after E2 treatment (Abraham et al., 2003). In contrast, the time profile of estrogen-induced CREB phosphorylation in BFC cells was more transient (peaked at 15 min or $1 \mathrm{~h}$ ), and there was no effect at $4 \mathrm{~h}$. This time profile of CREB activation may reflect a substantial difference in the estrogen-sensitive signaling process, which induces CREB phosphorylation in cholinergic neurons compared with $\mathrm{GnRH}$ neurons. The origin of cell type differences in estrogen-induced CREB phosphorylation can be derived from the different expression of ERs between GnRH and cholinergic neurons. Although GnRH neurons predominantly express ER $\beta$ (Herbison and Pape, 2001), cholinergic neurons mainly express ER $\alpha$ (Shughrue et al., 2000; Kalesnykas et al., 2005), and indeed we found that estrogeninduced increase in PCREB-IR in cholinergic neurons was completely blocked in $\mathrm{ER} \alpha \mathrm{KO}$ mice. Furthermore, in the striatum, where no $\mathrm{ER} \alpha$ is present in cholinergic neurons (Shughrue et al., 2000), E2 failed to increase CREB phosphorylation in these neurons. Surprisingly, estrogen-induced CREB phosphorylation was partially suppressed in ER $\beta$ KO compared with WT mice in MSDB. One possible explanation is that $\mathrm{ER} \alpha$ expression decreases in $\mathrm{ER} \beta \mathrm{KO}$ mice. Recently, Bora et al. (2005) demonstrated that the level of $\operatorname{ER} \alpha$ mRNA decreased in the septal region in $\mathrm{ER} \beta \mathrm{KO}$ mice, which may implicate a partial effect of estrogen on CREB phosphorylation in MS-DB in ER $\beta$ KO mice. Nevertheless, we showed that the rapid, E2-induced phosphorylation of CREB is critically dependent on $\mathrm{ER} \alpha$ in vivo.

In terms of estrogen-induced CREB phosphorylation, we found that cholinergic neurons are different not only from $\mathrm{GnRH}$ neurons, but they show an area specific activation pattern and signaling in different cholinergic regions. Although estrogen induces phosphorylation of CREB in cholinergic neurons in MS-DB with an apparent maximal increase at $1 \mathrm{~h}$, in the SI, the estrogen-induced CREB phosphorylation was significant only at 
15 min. The region specificity suggests that different signaling mechanisms exist in cholinergic neurons on a topographical basis. Therefore, we investigated the role of PKA and MAPK pathways, because these pathways show estrogen sensitivity and are potential regulators of CREB phosphorylation. We demonstrated that estrogen-induced CREB phosphorylation in cholinergic neurons was completely blocked by the inhibition of p42/44 MAPK via blocking MEK1/2 in both SI and MS-DB, but blocking PKA was effective only in SI. Because PKA can activate the MAPK pathway and consequently CREB phosphorylation, we suggest that estrogen can induce CREB phosphorylation via a coupled PKA-MAPK pathway in SI but involves only the MAPK pathway in MS-DB. Such a difference may play a role in the different time profile of estrogen-induced CREB phosphorylation observed in cholinergic neurons of the different regions.

Our results indicate that $\mathrm{ER} \alpha$ and the PKA-MAPK pathway plays an important role in estrogen-induced CREB phosphorylation in cholinergic neurons; however, the precise mechanism for activation of the PKA-MAPK signaling system via liganded ER $\alpha$ is unknown. Several examples of ER actions have been reported to involve phosphatidyl inositol 3-kinase, Src kinases, and G-protein-coupled receptors leading to consequent activation of PKA, MEK1/2, and CREB (Honda et al., 2000; Carlstrom et al., 2001; Zhao et al., 2005). Additional studies are needed to determine how the liganded ER $\alpha$ activates the PKA-MAPK pathway in cholinergic neurons.

\section{The possible functional consequences of estrogen-induced CREB phosphorylation in basal forebrain cholinergic neurons}

The most pressing question of the effects of estrogen on CREB phosphorylation in cholinergic neurons is its physiological relevance. The level of pCREB was higher in proestrus SHAM mice than in OVX animals in cholinergic neurons of MS-DB and SI, indicating that circulating, physiological concentration of estrogen can affect the cholinergic system via CREB phosphorylation.

One aspect of these data may clarify the role of BFC in the estrogen sensitivity of the hippocampal functions. Estrogen may stimulate acetylcholine release in the hippocampus via acting on cholinergic cells of MS-DB (Gibbs et al., 1997) and thereby influences GABAergic synapses in the hippocampus (Rudick et al., 2003). However, additional experiments are needed to evaluate the role of CREB in the estrogen-induced increase in acetylcholine synthesis and cholinergic functions of medial septal cholinergic neurons.

The other aspect may relate to the cytoprotective actions of estrogen. It is well known that cholinergic cells within the substantia innominata are highly vulnerable in some neurodegenerative models such as Alzheimer's disease, hypoxia, and ischemia (Whitehouse et al., 1982; Coyle et al., 1983; Brandel et al., 1991; Wenk and Willard, 1998), and estrogen has ameliorative effects in such degenerative diseases. Some findings indicate that classical ERs mediate these ameliorative actions, because they can be blocked by ER antagonists, and these are absent in ER $\alpha \mathrm{KO}$ animals (Wilson et al., 2000; Dubal et al., 2001). Although the role of ER-mediated CREB activation is uncertain in estrogeninduced protective mechanisms, CREB has been linked as a key transcription factor in many neuroprotective effects (Finkbeiner et al., 1997; Walton and Dragunow, 2000). A number of genecoding proteins with antiapoptotic effects such as $\mathrm{Bcl}_{2}, \mathrm{Bcl}_{\mathrm{xl}}$, and BDNF (Tao et al., 1998; Pugazhenthi et al., 2000; Saini et al., 2004) contain CRE in its promoters, suggesting an important role for CREB-regulated transcriptional activity in neuronal survival.
It remains to be determined whether the estrogen-sensitive CREmediated transcription has a role in neuronal survival in the BFC system.

In summary, this study demonstrates that estrogen has a nonclassical effect in a nonreproductive neuronal population, involving cholinergic neurons, and provides the first in vivo evidence for the presence of functionally active $\mathrm{ER} \alpha$ in nonclassical actions in cholinergic neurons. Furthermore, these findings reveal a region-specific role of PKA-MAPK signaling system in E2induced CREB phosphorylation in cholinergic neurons. Finally, these observations suggest that estrogen-induced nonclassical actions have physiological importance in the cholinergic functions.

\section{References}

Abraham IM, Herbison AE (2005) Major sex differences in non-genomic estrogen actions on intracellular signaling in mouse brain in vivo. Neuroscience 131:945-951.

Abraham IM, Han SK, Todman MG, Korach KS, Herbison AE (2003) Estrogen receptor $\beta$ mediates rapid estrogen actions on gonadotropinreleasing hormone neurons in vivo. J Neurosci 23:5771-5777.

Abraham IM, Todman MG, Korach KS, Herbison AE (2004) Critical in vivo roles for classical estrogen receptors in rapid estrogen actions on intracellular signaling in mouse brain. Endocrinology 145:3055-3061.

Aggarwal P, Gibbs RB (2000) Estrogen replacement does not prevent the loss of choline acetyltransferase-positive cells in the basal forebrain following either neurochemical or mechanical lesions. Brain Res 882:75-85.

Baum LW (2005) Sex, hormones, and Alzheimer's disease. J Gerontol A-Biol 60:736-743.

Beninger RJ, Wirsching BA, Jhamandas K, Boegman RJ (1989) Animal studies of brain acetylcholine and memory. Arch Gerontol Geriatr 1:71-89.

Bora SH, Liu Z, Kecojevic A, Merchenthaler I, Koliatsos VE (2005) Direct, complex effects of estrogens on basal forebrain cholinergic neurons. Exp Neurol 194:506-522.

Brandel JP, Hirsch EC, Malessa S, Dukyckaerts C, Cervera P, Agid Y (1991) Differential vulnerability of cholinergic projections to mediodorsal nucleus of the thalamus in senile dementia of Alzheimer type and progressive supranuclear palsy. Neuroscience 41:25-31.

Carlstrom L, Ke ZJ, Unnerstall JR, Cohen RS, Pandey SC (2001) Estrogen modulation of the cyclic AMP response element-binding protein pathway. Effects of long-term and acute treatments. Neuroendocrinology 74:227-243.

Cervo L, Mukherjee S, Bertaglia A, Samanin R (1997) Protein kinases A and $\mathrm{C}$ are involved in the mechanisms underlying consolidation of cocaine place conditioning. Brain Res 775:30-36.

Coyle JT, Price DL, DeLong MR (1983) Alzheimer's disease: a disorder of cortical cholinergic innervation. Science 219:1184-1190.

Dubal DB, Zhu H, Yu J, Rau SW, Shughrue PJ, Merchenthaler I, Kindy MS, Wise PM (2001) Estrogen receptor alpha, not beta, is a critical link in estradiol-mediated protection against brain injury. Proc Natl Acad Sci USA 98:1952-1957.

Falkenstein E, Tillmann H-C, Christ M, Feuring M, Wehling M (2000) Multiple actions of steroid hormones-a focus on rapid, nongenomic effects. Pharmacol Rev 52:513-552.

Finkbeiner S, Tavazoie SF, Maloratsky A, Jacobs KM, Harris KM, Greenberg ME (1997) CREB: a major mediator of neuronal neurotrophin responses. Neuron 19:1031-1047.

Gabor R, Nagle R, Johnson DA, Gibbs RB (2003) Estrogen enhances potassium-stimulated acetylcholine release in the rat hippocampus. Brain Res 962:244-247.

Gibbs RB (2003) Effects of ageing and long-term hormone replacement on cholinergic neurones in the medial septum and nucleus basalis magnocellularis of ovariectomized rats. J Neuroendocrinol 15:477-485.

Gibbs RB, Hashash A, Johnson DA (1997) Effects of estrogen on potassiumstimulated acetylcholine release in the hippocampus and overlying cortex of adult rats. Brain Res 749:143-146.

Gibbs RB, Gabor R, Cox T, Johnson DA (2004) Effects of raloxifene and estradiol on hippocampal acetylcholine release and spatial learning in the rat. Psychoneuroendocrinology 29:741-748.

Gonzalez GA, Yamamoto KK, Fischer WH, Karr D, Menzel P, Biggs III W, Vale WW, Montminy MR (1989) A cluster of phosphorylation sites on 
the cyclic AMP-regulated nuclear factor CREB predicted by its sequence. Nature 337:749-752.

Grimaldi CM, Hill L, Xu X, Peeva E, Diamond B (2005) Hormonal modulation of B cell development and repertoire selection. Mol Immunol 42:811-820.

Gu G, Rojo AA, Zee MC, Yu J, Simerly RB (1996) Hormonal regulation of CREB phosphorylation in the anteroventral periventricular nucleus. J Neurosci 16:3035-3044.

Guerra B, Diaz M, Alonso R, Martin R (2004) Plasma membrane oestrogen receptor mediates neuroprotection against beta-amyloid toxicity through activation of Raf-1/MEK/ERK cascade in septal-derived cholinergic SN56 cells. J Neurochem 91:99-109.

Han BH, Holtzman DM (2000) BDNF protects the neonatal brain from hypoxic-ischemic injury in vivo via the ERK pathway. J Neurosci 20:5775-5781.

Herbison AE, Pape JR (2001) New evidence for estrogen receptors in gonadotropin-releasing hormone neurons. Front Neuroendocrinol 22:292-308.

Hertelendy F, Zakar T (2004) Regulation of myometrial smooth muscle functions. Curr Pharm Design 10:2499-2517.

Honda K, Sawada H, Kihara T, Urushitani M, Nakamizo T, Akaike A, Shimohama S (2000) Phosphatidylinositol 3-kinase mediates neuroprotection by estrogen in cultured cortical neurons. J Neurosci Res 60:321-327.

Horvath KM, Hartig W, Van der Veen R, Keijser JN, Mulder J, Ziegert M, Van der Zee EA, Harkany T, Luiten PG (2002) 17beta-estradiol enhances cortical cholinergic innervation and preserves synaptic density following excitotoxic lesions to the rat nucleus basalis magnocellularis. Neuroscience 110:489-504.

Kalesnykas G, Roschier U, Puolivali J, Wang J, Miettinen R (2005) The effect of aging on the subcellular distribution of estrogen receptor-alpha in the cholinergic neurons of transgenic and wild-type mice. Eur J Neurosci 21:1437-1442.

Karpuzoglu-Sahin E, Zhi-Jun Y, Lengi A, Sriranganathan N, Ansar Ahmed S (2001) Effects of long-term estrogen treatment on IFN-gamma, IL-2 and IL-4 gene expression and protein synthesis in spleen and thymus of normal C57BL/6 mice. Cytokine 14:208-217.

Kim JS, Kim HY, Kim JH, Shin HK, Lee SH, Lee YS, Son H (2002) Enhancement of rat hippocampal long-term potentiation by 17 beta-estradiol involves mitogen-activated protein kinase-dependent and -independent components. Neurosci Lett 332:65-69.

Krege JH, Hodgin JB, Couse JF, Enmark E, Warner M, Mahler JF, Sar M, Korach KS, Gustafsson JA, Smithies O (1998) Generation and reproductive phenotypes of mice lacking estrogen receptor beta. Proc Natl Acad Sci USA 95:15677-15682.

Lee B, Butcher GQ, Hoyt KR, Impey S, Obrietan K (2005) Activitydependent neuroprotection and cAMP response element-binding protein (CREB): kinase coupling, stimulus intensity, and temporal regulation of CREB phosphorylation at serine 133. J Neurosci 25:1137-1148.

Leranth Cs, Roth RH, Elswoth JD, Naftolin F, Horvath TL, Redmond Jr DE (2000) Estrogen is essential for maintaining negrostriatal dopamine neurons in primates: implications for Parkinson's disease and memory. J Neurosci 20:8604-8609.

Lonze BE, Ginty DD (2002) Function and regulation of CREB family transcription factors in the nervous system. Neuron 35:605-623.

Lubahn DB, Moyer JS, Golding TS, Couse JF, Korach KS, Smithies O (1993) Alteration of reproductive function but not prenatal sexual development after insertional disruption of the mouse estrogen receptor gene. Proc Natl Acad Sci USA 90:11162-11166.

Maccioni RB, Munoz JP, Barbeito L (2001) The molecular bases of Alzheimer's disease and other neurodegenerative disorders. Arch Med Res 32:367-381.

Matthies H, Schulz S, Thiemann W, Siemer H, Schmidt H, Krug M, Hollt V (1997) Design of a multiple slice interface chamber and application for resolving the temporal pattern of CREB phosphorylation in hippocampal long-term potentiation. J Neurosci Methods 78:173-179.

Mayr B, Montminy M (2001) Transcriptional regulation by the phosphorylation dependent factor CREB. Nat Rev Mol Cell Bio 2:599-609.
McEwen B (2002) Estrogen actions throughout the brain. Recent Prog Horm Res 57:357-384.

McNulty S, Schurov IL, Sloper PJ, Hastings MH (1998) Stimuli which entrain the circadian clock of the neonatal Syrian hamster in vivo regulate the phosphorylation of the transcription factor CREB in the suprachiasmatic nucleus in vitro. Eur J Neurosci 10:1063-1072.

Paxinos G, Franklin KBJ (2001) The mouse brain in stereotaxic coordinates. San Diego: Academic.

Pugazhenthi S, Nesterova A, Sable C, Heidenreich KA, Boxer LM, Heasley LE, Reusch JE (2000) Akt/protein kinase B up-regulates Bcl-2 expression through cAMP-response element-binding protein. J Biol Chem 275:10761-10766.

Purves-Tyson TD, Keast JR (2004) Rapid actions of estradiol on cyclic AMP response-element binding protein phosphorylation in dorsal root ganglion neurons. Neuroscience 129:629-637.

Rahmouni K, Morgan DA, Morgan GM, Liu X, Sigmund CD, Mark AL, Haynes WG (2004) Hypothalamic PI3K and MAPK differentially mediate regional sympathetic activation to insulin. J Clin Invest 114:652-658.

Rossi R, Grimaldi T, Origliani G, Fantini G, Coppi F, Modena MG (2002) Menopause and cardiovascular risk. Pathophysiol Haemost Thromb 32:325-328.

Rudick CN, Gibbs RB, Woolley CS (2003) A role for the basal forebrain cholinergic system in estrogen-induced disinhibition of hippocampal pyramidal cells. J Neurosci 23:4479-4490.

Saini HS, Gorse KM, Boxer LM, Sato-Bigbee C (2004) Neurotrophin-3 and a CREB-mediated signaling pathway regulate Bcl-2 expression in oligodendrocyte progenitor cells. J Neurochem 89:951-961.

Saunders-Pullman R (2003) Estrogens and Parkinson disease: neuroprotective, symptomatic, neither, or both? Endocrine 21:81-87.

Shughrue PJ, Scrimo PJ, Merchenthaler I (2000) Estrogen binding and estrogen receptor characterization (ERalpha and ERbeta) in the cholinergic neurons of the rat basal forebrain. Neuroscience 96:41-49.

Simoncini T, Mannella P, Fornari L, Caruso A, Varone G, Genazzani AR (2004) Genomic and non-genomic effects of estrogens on endothelial cells. Steroids 69:537-542.

Tao X, Finkbeiner S, Arnold DB, Shaywitz AJ, Greenberg ME (1998) $\mathrm{Ca}^{2+}$ influx regulates BDNF transcription by a CREB family transcription factor-dependent mechanism. Neuron 20:709-726.

Vasudevan N, Kow LM, Pfaff D (2005) Integration of steroid hormone initiated membrane action to genomic function in the brain. Steroids 70:388-396.

von Gall C, Duffield GE, Hastings MH, Kopp MD, Dehghani F, Korf HW, Stehle JH (1998) CREB in the mouse SCN: a molecular interface coding the phase-adjusting stimuli light, glutamate, PACAP, and melatonin for clockwork access. J Neurosci 18:10389-10397.

Walton MR, Dragunow I (2000) Is CREB a key to neuronal survival? Trends Neurosci 23:48-53.

Wenk GL, Willard LB (1998) The neural mechanisms underlying cholinergic cell death within the basal forebrain. Int J Dev Neurosci 16:729-735.

Whitehouse PJ, Price DL, Struble RG, Clark AW, Coyle JT, Delon MR (1982) Alzheimer's disease and senile dementia: loss of neurons in the basal forebrain. Science 215:1237-1239.

Wilson ME, Dubal DB, Wise PM (2000) Estradiol protects against injuryinduced cell death in cortical explant cultures: a role for estrogen receptors. Brain Res 873:235-242.

Zaborszky L, Pang K, Somogyi J, Nadasdy Z, Kallo I (1999) The basal forebrain corticopetal system revisited. Ann NY Acad Sci 877:339-367.

Zhao L, Chen S, Ming Wang J, Brinton RD (2005) 17beta-Estradiol induces $\mathrm{Ca}(2+)$ influx, dendritic and nuclear $\mathrm{Ca}(2+)$ rise and subsequent cyclic AMP response element-binding protein activation in hippocampal neurons: a potential initiation mechanism for estrogen neurotrophism. Neuroscience 132:299-311.

Zhou Y, Watters JJ, Dorsa DM (1996) Estrogen rapidly induces the phosphorylation of the cAMP response element binding protein in rat brain. Endocrinology 137:2163-2166.

Zhu W, Smart EJ (2003) Caveolae, estrogen and nitric oxide. Trends Endocrinol Metab 14:114-117. 